\title{
RESUME SECTION VIII STUDI KASUS AUDIT PERUSAHAAN
}

\author{
Adit Kusnandar \\ 165100069 \\ Fakultas Komputer \\ Aditkusnandra.student@umitra.ac.id
}

\begin{abstract}
Tahap kebijakan ini, tim manajemen Perusahaan Umum Jaminan Kredit Indonesia menyetujui dilakukannya audit sistem informasi untuk menemukan permasalahan yang terjadi pada proses kerja layana KUR.
\end{abstract}

Tahap perencanaan sistem, auditor mengumpulkan data primer dan sekunder, seperti hasil kuisioner, data nasabah, ktp, surat ijin usaha, surat riwayat belum pernah mengambil KUR, form pengajuan KUR, dan surat keterangan usaha.

Teknik pengumpulan data yang digunakan antara lain wawancara, observasi, kuisioner, dan studi pustaka. Pada audit sistem informasi layanan KUR memiliki ruang lingkup kerangka kerja COBIT yang berawal dari penyebaran kuisioner yang dilakukan peneliti kepada pihak-pihak terkait.

Kata Kunci : Kebijakan dan Perencanaan Sistem.

\section{A. RESUME}

\section{Analisi Sistem}

Setelah pada tahap kebijakan dan perencanaan sistem tahap selanjutnya adalah Analisis Sistem. Berikut adalah komponen yang harus ada layanan KUR : $\checkmark$ Petugas KUR Bank

$\checkmark$ Nasabah Bank

$\checkmark$ Form Pengajuan KUR

$\checkmark$ Petugas Bank

$\checkmark$ Staff Bisnis

$\checkmark$ Kepala Unit Bisnis

$\checkmark$ Sertifikat Pengajuan KUR 
Analisis kelemahan sistem KUR antara lain Kredit macet oleh nasabah bank karena kurangnya analisis kelayakan yang tepat dalam pemberian acc pengajuan KUR.

Pemeriksaan Lapangan (Fieldwork)

Tahapan pemeriksaan lapangan antara lain :

- Pemeriksaan Data Bukti

- Kuisioner

- Hasil Pengolahan Data Kuisioner

Pelaporan (Reporting)

Setelah kuisioner disebarkan maka akan diadapat data yang akan diproses untuk dihitung berdasrkan perhitungan maturity level. Berikut tahapan pelaporan, yaitu :

a. Hasil audit berisi temuan sekarang (performance maturity level) dan harapan pada masa yang akan datang (expected maturity level).

b. Analisis Gap dilakukan analisa interpretasi hasil performance maturity level dan expected.

c. Rekomendasi berisi tindakan korektif mengatasi gap yang dilakukanuntuk mencapai perbaikan.

d. Tindakan ini bagaimana menghasilkan nilai pengolahan data yang optimal.

Tindak Lanjut (Follow up)

Setelah rekomendasi diserahkan kepada pihak manajemen Perum Jamkrindo untuk selanjutnya dilakukan review oleh manajemen sehingga menjadikan audit ini sebagai acuan untuk mengembangkan sistem informasi layanan KUR.

\section{B. ID SECURITY \\ QWTD4452377-ASP-5244107}

\section{REFERENCE}

[1] O. M. Febriani and A. S. Putra, "Sistem Informasi Monitoring Inventori Barang Pada Balai Riset Standardisasi Industri Bandar Lampung," J. Inform., vol. 13, no. 1, pp. 90-98, 2014.

[2] A. S. Putra, "Paperplain: Execution Fundamental Create Application With Borland Delphi 7.0 University Of Mitra Indonesia," 2018.

[3] A. S. Putra, "2018 Artikel Struktur Data, Audit Dan Jaringan Komputer," 2018.

[4] A. S. Putra, "ALIAS MANAGER USED IN DATABASE DESKTOP STUDI CASE DB DEMOS."

[5] A. S. Putra, "COMPREHENSIVE SET OF PROFESSIONAL FOR DISTRIBUTE COMPUTING."

[6] A. S. Putra, "DATA ORIENTED RECOGNITION IN BORLAND DELPHI 7.0."

[7] A. S. Putra, "EMBARCADERO DELPHI XE 2 IN GPUPOWERED FIREMONKEY APPLICATION." 
[8] A. S. Putra, "HAK ATAS KEKAYAAN INTELEKTUAL DALAM DUNIA TEKNOLOGY BERBASIS REVOLUSI INDUSTRI 4.0."

[9] A. S. Putra, "IMPLEMENTASI PERATURAN PERUNDANGAN UU. NO 31 TAHUN 2000 TENTANG DESAIN INDUSTRI BERBASIS INFORMATION TECHNOLOGY."

[10] A. $\quad$ S. $\quad$ Putra, "IMPLEMENTATION OF PARADOX DBASE." A. S. Putra, "IMPLEMENTATION OF TRADE SECRET CASE STUDY SAMSUNG MOBILE PHONE."

[12] A. S. Putra, "IMPLEMENTATION PATENT FOR APPLICATION WEB BASED CASE STUDI WWW. PUBLIKLAMPUNG. COM."

[13] A "IMPLEMENTATION SYSTEM FIRST TO INVENT IN DIGITALLY INDUSTRY."

[14] A. S. Putra, "MANUAL REPORT \& INTEGRATED DEVELOPMENT

ENVIRONMENT BORLAND DELPHI 7.0."

[15] A. S. Putra, "PATENT AS RELEVAN "SUPPORT RESEARCH."

[16] A. S. Putra, "PATENT FOR RESEARCH STUDY CASE OF APPLE. Inc."

[17] A. S. Putra, "PATENT PROTECTION FOR APPLICATION INVENT."

[18] A. S. Putra, "QUICK REPORT
IN PROGRAMMING."

[19] A. S. Putra, "REVIEW CIRCUIT LAYOUT COMPONENT

REQUIREMENT ON ASUS NOTEBOOK."

[20] A. S. Putra, "REVIEW TRADEMARK PATENT FOR INDUSTRIAL TECHNOLOGY BASED 4.0.”

[21] A. S. Putra, "TOOLBAR COMPONENT PALLETTE IN OBJECT ORIENTED PROGRAMMING."

[22] A. S. Putra, "WORKING DIRECTORY SET FOR PARADOX 7."

[23] A. S. Putra, "ZQUERY CONNECTION

IMPLEMENTED

PROGRAMMING STUDI CASE PT. BANK BCA Tbk."

[24] A. S. Putra, D. R. Aryanti, and I. Hartati, "Metode SAW (Simple Additive Weighting) sebagai Sistem Pendukung Keputusan Guru Berprestasi (Studi Kasus: SMK Global Surya)," in Prosiding Seminar Nasional Darmajaya, 2018, vol. 1, no. 1, pp. 85-97.

[25] A. S. Putra and O. M. Febriani, "Knowledge Management Online Application in PDAM Lampung Province," in Prosiding International conference on Information Technology and Business (ICITB), 2018, pp. 181-187.

[26] A. S. Putra, O. M. Febriani, and B. Bachry, "Implementasi Genetic Fuzzy System Untuk Mengidentifikasi Hasil Curian Kendaraan Bermotor Di Polda 
Lampung," SIMADA (Jurnal

Sist. Inf. dan Manaj. Basis

Data), vol. 1, no. 1, pp. 21-30, 2018.

[27] A. S. Putra, H. Sukri, and K. Zuhri, "Sistem Monitoring Realtime Jaringan Irigasi Desa (JIDES) Dengan Konsep Jaringan Sensor Nirkabel," IJEIS (Indonesian J. Electron. Instrum. Syst., vol. 8, no. 2, pp. 221-232.

[28] D. P. Sari, O. M. Febriani, and A. S. Putra, "Perancangan Sistem Informasi SDM Berprestasi pada SD Global Surya," in Prosiding Seminar Nasional Darmajaya, 2018, vol. 1, no. 1, pp. 289-294. 